\title{
ON THE SOLUTION OF ENERGY BALANCE EQUATION SYSTEM TO PREDICT TEMPERATURE DISTRIBUTION IN THE BUILDING ELEMENTS WITH VENTILATED AIR GAP
}

\author{
Edmundas MONSTVILAS, Karolis BANIONIS, Jurga PODERYTE \\ Raimondas BLIŪDŽIUS, Arūnas BURLINGIS \\ Institute of Architecture and Construction of Kaunas University of Technology, \\ Tunelio g. 60, 44405 Kaunas, Lithuania
}

Received 10 Apr 2014; accepted 10 Jun 2014

\begin{abstract}
The article presents the solution of heat balance equation system, describing heat exchange processes in ventilated envelopes, which was applied to derive formulas for the calculation of temperatures in the ventilated layers of the envelopes. The accurateness of the formulas was assessed by experimental research and analysis of the calculation results. During the process of heat exchange balance equation solution, the equations were simplified by introducing the following restriction into the derived formulas: they may only be applied for the ventilated envelopes with steel or similar coatings as their external layers, i.e. coatings having small heat capacity and minor difference between the external and internal surface temperatures. The derived formulas enable the calculation of the temperatures of the ventilated envelopes in the distance which does not exceed a half of the ventilated air gap length measuring from the air entrance into the gap. However, this restriction does not impede the estimation of the average thermal indicators of the ventilated envelopes.
\end{abstract}

Keywords: ventilated roof, temperature distribution, heat flow balance, energy balance, selective coatings.

\section{Introduction}

In the European Union, considerable attention is directed towards reducing the use of energy in buildings; thus, in the future, only low energy buildings are going to be constructed (Directive 2010/31/EU 2010). The less energy is used in a building, the more accurate are the calculation methods used for its design. Their accuracy is usually directly proportionate to their complexity, and complex methods are difficult to understand and apply. For this reason, in the development of normative EC calculation methods, the focus is on the methods which are simple and accurate enough (Van Dijk et al. 2005). They usually involve the use of empirical formulas or formulas describing processes in steady-state conditions.

One of the constituents of energy consumption is heat gains/losses (HGL) through the envelopes of the building. They depend on the thermal properties of the envelopes, temperature of the premises and climatic impact on the envelopes. Identical climatic parameters have different influence on different envelopes, which is why the assessment of the parameters differs in the calculation of HGL through the envelopes depending on their types. For example, the impact of sky radiation on vertical walls is twice less than on horizontal roofs (EN ISO 13790:2008). HGL through roofs and other non-transparent envelopes are mostly influenced by the following climatic impacts: outdoor temperature, wind speed, solar radiation and long-wave radiation from sky (Filho et al. 2011). These climatic impacts are differently absorbed by the envelopes of the same type, because other factors, such as specific construction and surface qualities of envelopes, are also influential.

HGL heat flow rate through non-transparent, non-ventilated envelopes in steady-state conditions is calculated by multiplying heat transmittance of the envelope by the difference of temperatures between external surfaces and premises. The surface temperature poses the main problem in the calculation process because its value depends on both heat transmittance of the envelope and climatic impacts (outdoor temperature, wind speed, solar radiation and long-wave radiation from sky). Thus, HGL heat flow rate through non-ventilated envelopes is calculated by applying heat balance equation which considers climatic impacts, thermal properties of the envelopes and heat exchange, taking place inside the envelopes and on their surfaces (Suehrcke et al. 2008). 


\section{Literature review}

In the ventilated envelopes, heat exchange between outdoor and premises is more complicated than in nonventilated ones where the following heat exchange processes take place in steady-state conditions (Infield et al. 2004): radiation and convective heat exchange with the environment in external surfaces of the envelopes; convective heat exchange between boundary surfaces of the ventilated air gap and air moving in the gap; radiation heat exchange between boundary surfaces of the ventilated air gap; exit/entrance of a part of heat together with outdoor air entering the ventilated air gap; heat exchange by heat transmission through the layer of the envelope between the ventilated air gap and premises; convective and radiation heat exchange between internal surface of the envelope and premises.

HGL heat flow rate through non-transparent, non -ventilated envelopes in steady-state conditions could be easily calculated if heat transmittance of the part of the envelope between the premises and internal surface of the ventilated air gap, and the temperature difference between the premises and external surface of the thermal insulation layer (internal surface of the ventilated air gap) were known. These values of heat transmittance and temperature of the premises are usually known. However, in this case, it is most difficult to estimate the temperature of the external surface of thermal insulation layer, because its values depends on climatic impacts and the intensity of all the mentioned heat exchange processes in the ventilated envelopes.

The intensity of radiation heat exchange with the environment in external surfaces of the ventilated and non-ventilated envelopes depends on the values of solar radiation absorption coefficient $\alpha$ and emission $\varepsilon$ of these surfaces (Synnefa et al. 2006, 2007; Shi, Zhang 2011). The intensity of convective heat exchange between the boundary surfaces of the ventilated air gap and air flowing in the gap depends on the air flow speed (Banionis et al. 2011; Monstvilas et al. 2005). Moreover, emission of the boundary surfaces of the ventilated air gap determines the intensity of radiation heat exchange between these surfaces (Roels, Deurinck 2011). Due to outdoor air entering the ventilated air gap, the intensity of heat exchange is governed by the size of the gap and air flow speed in it (Ciampi et al. 2003). The intensity of heat exchange by heat transmittance through the layer of the envelope between the ventilated air gap and premises depends on the thermal resistance of the layer (Ciampi et al. 2005). Finally, air flow speed on the surface of the envelope, and emission of the surfaces of the envelope and premises determine the intensity of convective and radiation heat exchange between the internal surface of the envelope and premises (EN ISO 6946:2007). All values of the mentioned indicators and heat exchange processes in the ventilated envelopes as well as climatic indicators are known. However, no method for the calculation of the temperatures of the layers of the ventilated envelopes and heat flows through them, assessing all the mentioned heat exchange processes in such envelopes, has been developed yet. In EN ISO 6946:2007 calculation method, it is accepted that the temperature in the ventilated air gaps of the envelopes corresponds to the outdoor temperature. In contrast, the data of research demonstrate (Susanti et al. 2011) that due to various heat exchange processes, which take place in the ventilated air gaps, the temperature of the gaps may not be equated to the outdoor temperature.

In this paper, the analysis of heat exchange processes in the ventilated envelopes was performed, the heat balance equation system, describing the processes, was solved and formulas for calculating the temperature of the ventilated envelope layers were devised. In addition, experimental research of ventilated roofs was also carried out and the accuracy of the devised formulas was assessed on the basis of experimental and calculation results.

\section{Mathematical model of heat exchange in the ventilated envelopes}

In steady-state conditions, all heat exchange processes between the ventilated envelope and premises may be described by an equation system composed of four heat flow rate balance Eqns (1)-(4) (Fig. 1):

$$
\begin{aligned}
& q_{r, \text { sol.sw-ec.se }}+q_{r, \text { lw,ec.se-lw.ec.e }}=q_{c+r, e c . s e-e} \\
& +q_{\text {cond,ec.se-ec.si }} ; \\
& q_{c o n d, e c . s e-e c . s i}=q_{c, \text { ec.si-a.g.air }}+q_{r, e c . s i-i n s . s e} ; \\
& q_{c, \text { ec.si-a.g.air }}=q_{c, \text { a.g.air }}+q_{c, \text { a.g.air-ins.se }} ; \\
& q_{r, \text { ec.si-ins.se }}+q_{c, \text { a.g.air-ins.se }}=q_{\text {cond }+ \text { cins.se-i }},
\end{aligned}
$$

where: $q_{r, s o l . s w-e c . s e}$ - heat flow rate of short wave solar radiation to external covering of the ventilated building element; $q_{r, l w, e c . s e-l w . e c . e}$ - heat flow rate of long wave solar radiation to external covering of the ventilated building element; $q_{c+r, e c . s e-e}-$ convective and radiative heat flow rate from external covering of the ventilated building element to the sky; $q_{\text {cond,ec.se-ec.si }}$ - conductive heat flow rate from from the external coating of the envelope to the internal surface of external covering of the ventilated building element; $q_{c, \text { cec.si-a.g.air }}$ - convective heat flow rate from internal surface of external covering of the ventilated building element to ventilated air gap; $q_{r \text {,ec.si-ins.se }}{ }^{-}$ radiative heat flow rate from internal surface of external covering of the ventilated building element to ventilated air gap; $q_{c, \text { a.g.air }}-$ convective heat flow rate through the ventilated air gap; $q_{c, \text { a.g.air-ins.se }}-$ convective heat flow rate from ventilated air gap to the external surface of the thermal insulation layer; $q_{r, \text { ec.si-ins.se }}$ - radiative heat flow rate from internal surface of external covering of the ventilated building element to the external surface of thermal insulation layer; $q_{\text {cond }+ \text { c, ins.se-I }}$ - conductive heat flow rate from the external surface of thermal insulation layer in to the premises. 


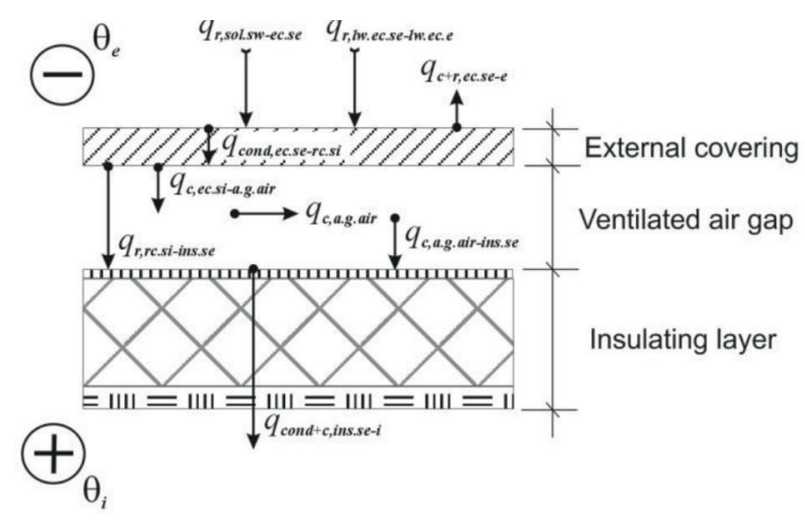

Fig. 1. Principal scheme of the ventilated envelope and heat flow rates describing heat exchange processes in the envelope

Eqn (1) takes into account that the sum of heat flow rates, affecting the envelope surface due to solar radiation $q_{r, s o l, s w-e c . s e}$ and long-wave radiation from sky $q_{r, l w . e c . s e-l w . e c . e}$, equals to the sum of heat flow rates, transmitted by radiation and convection from the envelope surface to the environment $q_{c+r \text {,ec.se-e }}$, and conductivity from the surface of external coating to of the envelope to the internal surface $q_{\text {cond,ec.se-ec.si }}$. Here $q_{r, l w-e c . s e}$ is the difference between the rates of heat flow, emitted from sky to the envelope surfaces, and flow from the surface to the environment; the value of $q_{r, l w-e c . s e}$ is negative. Eqn (2) takes into account that the rate $q_{\text {cond,ec.se-ec.si }}$ of heat flow, entering the internal surface of the external coating of the envelope from its external surface due to conductivity, equals to the sum of heat flow rates, transmitted from this internal surface to the ventilated air gap $q_{\text {c,ec.si-a.g.air by convection and from the same internal }}$ surface to the external surface of the thermal insulation layer $q_{\text {rec.si-ins.se }}$ by radiation. Eqn (3) takes into ac count that the rate $q_{c \text {,ec.si-a.g.air }}$ of heat flow, entering the ventilated air gap from the internal surface of the external coating of the envelope due to convection, equals to the sum of the rate $q_{c \text {,a.g.air }}$ of heat flow, moving outdoor from the ventilated air gap (due to the outdoor air entering the gap), and heat flow rate $q_{c \text {,a.g.air-ins.se }}$ of the air, moving in the external surface of the thermal insulation layer and the ventilated air gap due to convection. Eqn (4) takes into account that the sum of the rate $q_{c, e c . s i-a . g . a i r}$ of heat flow, entering the external surface of thermal insulation layer from the internal surface of the external coating of the envelope due to radiation, and heat flow rate $q_{c \text {,a.g.air-ins.se }}$ due to heat exchange between the external surface of thermal insulation layer and the air in the ventilated air gap equals to heat flow rate $q_{c o n d+c \text {, ins.se- } i}$ between the external surface of thermal insulation layer and premises (due to heat exchange by convection and permeability).

Every heat flow rate given in Eqns (1)-(4) may be described by the related indicators of the envelopes: the indicators of its layers and surfaces as well as their markings are given in Figure 2.

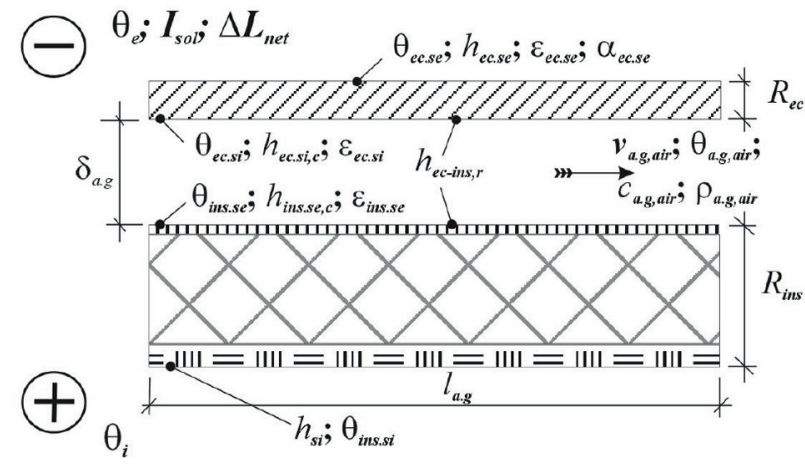

Fig. 2. Principal scheme of the ventilated envelope and indicators influencing its heat exchange

Eqns (1)-(4) system in the distance $l_{x}$ (when $l_{x} \leq 0.5 \cdot l_{\text {a.g. }}$ ) from the entrance of air into the ventilated gap may be rewritten as follows:

$$
\begin{aligned}
& I_{\text {sol }} \cdot \alpha_{e c . s e}+\Delta L_{n e t} \cdot \varepsilon_{e c . s e}=h_{e c . s e} \cdot\left(\theta_{e c . s e}-\theta_{e}\right) \\
& +1 / R_{e c} \cdot\left(\theta_{e c . s e}-\theta_{e c . s i}\right) ; \\
& 1 / R_{e c} \cdot\left(\theta_{e c . s e}-\theta_{e c . s i}\right)=h_{e c . s i, c} \cdot\left(\theta_{e c . s i}-\theta_{\text {a.g.air }}\right) \\
& +h_{e c-i n s, r} \cdot\left(\theta_{e c . s i}-\theta_{\text {ins.se }}\right) ; \\
& h_{e c . s i, c} \cdot\left(\theta_{e c . s i}-\theta_{\text {a.g.air }}\right)=0.5 / l_{x} \cdot \mathrm{c}_{\text {air }} \cdot \rho_{\text {air }} \cdot v_{\text {a.g.air }} \\
& \cdot \delta_{\text {a.g. }} \cdot\left(\theta_{\text {a.g.air }}-\theta_{e}\right)+h_{\text {ins.se, }} \cdot\left(\theta_{\text {a.g.air }}-\theta_{\text {ins.se }}\right) ; \\
& h_{\text {ec-ins, }, r} \cdot\left(\theta_{\text {ec.si }}-\theta_{\text {ins.se }}\right)+h_{\text {ins.se, },} \cdot\left(\theta_{\text {a.g.air }}-\theta_{\text {ins.se }}\right)= \\
& 1 /\left(R_{\text {ins }}+1 / h_{\text {si }}\right) \cdot\left(\theta_{\text {ins.se }}-\theta_{i}\right),
\end{aligned}
$$

where: $I_{\text {sol }}$ - intensity of total solar radiation to a surface of adequate orientation, $\mathrm{W} / \mathrm{m}^{2} ; \Delta L_{n e t}-$ the balance of long-wave radiation (the long-wave radiation of a surface minus the long-wave radiation from sky to a surface), $\left(\mathrm{W} / \mathrm{m}^{2}\right) ; \alpha_{e c . s e}-$ absorption coefficient of external covering of the ventilated building element for solar radiation; $\varepsilon_{e c . s e}-$ emissivity of external covering of the ventilated building element for long-wave thermal radiation; $h_{s i}$ - heat transfer coefficient of the internal surface of premises, $\mathrm{W} /\left(\mathrm{m}^{2} \cdot \mathrm{K}\right) ; h_{\text {ec.se }}$ - heat transfer coefficient of external covering of the ventilated building element, $\mathrm{W} /\left(\mathrm{m}^{2} \cdot \mathrm{K}\right) ; h_{\text {ec.si,c }}-$ convective heat transfer coefficient of internal surface of external covering of the ventilated building element, $\mathrm{W} /\left(\mathrm{m}^{2} \cdot \mathrm{K}\right) ; h_{\text {ins.se,c }}$ - convective heat transfer coefficient the external surface of the thermal insulation layer, $\mathrm{W} /\left(\mathrm{m}^{2} \cdot \mathrm{K}\right) ; h_{e c-i n s, r}$ - radiative heat transfer coefficient between internal surface of external covering of the ventilated building element and external surface of the thermal insulation layer, $\mathrm{W} /\left(\mathrm{m}^{2} \cdot \mathrm{K}\right) ; \theta_{\text {ec.se }}-$ external surface temperature of external covering of the ventilated building element, ${ }^{\circ} \mathrm{C} ; \theta_{\text {ec.si }}$ - internal surface temperature of external covering of the ventilated building element, ${ }^{\circ} \mathrm{C} ; \theta_{\text {a.g.air }}$ - ventilated air gap temperature, ${ }^{\circ} \mathrm{C}$; $\theta_{\text {ins.se }}$ - temperature of external surface of the thermal insulation layer, ${ }^{\circ} \mathrm{C} ; \theta_{e}-$ external temperature, ${ }^{\circ} \mathrm{C}$; $\theta_{i}$ - internal temperature, ${ }^{\circ} \mathrm{C} ; R_{e c}-$ thermal resistance of external covering of the ventilated building element, 
$\mathrm{m}^{2} \cdot \mathrm{K} / \mathrm{W} ; R_{\text {ins }}$ - thermal resistance of the insulation layer, $\mathrm{m}^{2} \cdot \mathrm{K} / \mathrm{W} ; l_{x}-$ length of ventilated air gap, $\mathrm{m} ; \delta_{a g}$. height of ventilated air gap, $\mathrm{m} ; \rho_{\text {air }} \cdot \mathrm{c}_{\text {air }}$ - heat capacity of the air per volume, $\rho_{\text {air }} \cdot \mathrm{c}_{\text {air }}=1200 \mathrm{~J} /\left(\mathrm{m}^{3} \cdot \mathrm{K}\right) ; v_{\text {a.g.air }}-$ air velocity in ventilated air gap, $\mathrm{m} / \mathrm{s}$.

According to Eqns (1)-(8), the rate $q_{\text {cond }+c \text {, ins.se-i }}$ of heat flow through the ventilated envelopes into premises depends on the difference between the temperatures of the external surface of thermal insulation layer $\theta_{\text {ins.se }}$ and premises $\theta_{i}$, rather than the difference between the outdoor temperature $\theta_{e}$ and temperature of the premises $\theta_{i}$ :

$$
q_{\text {cond }+ \text { c, ins.se }-i}=1 /\left(R_{\text {ins }}+1 / h_{\text {si }}\right) \cdot\left(\theta_{\text {ins.se }}-\theta_{i}\right) .
$$

Therefore, in order to determine the value of heat flow rate through the ventilated envelopes, it is necessary to estimate the temperature $\theta_{\text {ins.se }}$ of the external surface of thermal insulation layer which is influenced by all heat exchange processes taking place in the envelope. The calculation of this temperature requires solving a system of four Eqns (5)-(8) with four unknowns: $\theta_{\text {ec.se }}, \theta_{\text {ec.si }}$, $\theta_{\text {a.g.air }}$ and $\theta_{\text {ins.se }}$.

As the solution of four equations with four unknowns is complicated, it was necessary to simplify the equation system. The following argument was selected for this purpose: the rate of heat flow through the envelope layer having the least thermal resistance, which results in the smallest difference between the temperatures of external and internal surfaces of the layer, could be excluded from the calculations, i.e. the smaller the temperature difference through a respective layer of the ventilated envelope excluded from calculations, the lesser will be its influence on the final result. Since the materials used for the construction of external coatings of ventilated envelopes are usually rather thin, but their thermal permeability is high, thermal resistance of the coatings is low, which determines a small difference between the temperatures of the external and internal surfaces of the coating. In other words, the value of $\theta_{\text {ec.se }}$ is very close to that of $\theta_{\text {ec.si }}$. Extremely small differences of temperatures $\theta_{\text {ec.se }}$ and $\theta_{\text {ec.si }}$ may be observed when steel plates are used for constructing external coatings of the envelopes. The rate $q_{\text {cond,ec.se-ec.si }}$ of heat flow from the external to internal surface of external coating by permeability was eliminated from the four-equation system and the temperature $\theta_{e c . s e}$ of the external surface of the coating was used instead of the temperature $\theta_{\text {ec.si }}$. Thus, after the simplification, the heat flow rate balance equation system may be expressed as follows:

$$
\begin{gathered}
q_{r, \text { sol.sw-ec.se }}+q_{r, \text { lw,ec.se-lw.ec.e }}=q_{c+r, \text { ec.se-e }}+ \\
q_{c, \text { ec.se-a.g.air }}+q_{r, e c . s e-i n s . s e} \\
q_{c, \text { cec.se-a.g.air }}=q_{c, \text { a.g.air }}+q_{c, \text { a.g.air-ins.se }} ; \\
q_{r, \text { cc.se-inn.se }}+q_{c, \text { a.g.air-ins.se }}=q_{\text {cond }+ \text { c,ins.se- } i} .
\end{gathered}
$$

Having evaluated the indicators of climate as well as the layers and surfaces of the envelope, Eqns (10)-(12) in the distance $l_{x}$ (when $l_{x} \leq 0.5 \cdot l_{\text {a.g. }}$ ) from the entrance of air into the ventilated air gap may be written as follows:

$$
\begin{aligned}
& I_{\text {sol }} \cdot \alpha_{e c . s e}+\Delta L_{\text {net }} \cdot \varepsilon_{\text {ec.se }}=h_{\text {ec.se }} \cdot\left(\theta_{\text {ec.se }}-\theta_{e}\right) \\
& +h_{\text {ec.si,c }} \cdot\left(\theta_{\text {ec.se }}-\theta_{\text {a.g.air }}\right)+h_{e c-\text { ins }, r} \cdot\left(\theta_{\text {ec.se }}-\right. \\
& \left.\theta_{\text {ins.se }}\right) ; \\
& h_{\text {ec.si,c }} \cdot\left(\theta_{\text {ec.se }}-\theta_{\text {a.g.air }}\right)=0.5 / l_{x} \cdot c_{\text {air }} \cdot \rho_{\text {air }} \cdot v_{\text {a.g.air }} \cdot \\
& \delta_{\text {a.g }} \cdot\left(\theta_{\text {a.g.air }}-\theta_{e}\right)+h_{\text {ins.se, },} \cdot\left(\theta_{\text {a.g.air }}-\theta_{\text {ins.se }}\right) ; \\
& h_{\text {ec-ins, } r} \cdot\left(\theta_{\text {ec.se }}-\theta_{\text {ins.se }}\right)+h_{\text {ins.se,c }} \\
& \cdot\left(\theta_{\text {a.g.air }}-\theta_{\text {ins.se }}\right)=1 /\left(R_{\text {ins }}+1 / h_{\text {si }}\right) \cdot\left(\theta_{\text {ins.se }}-\theta_{i}\right) .
\end{aligned}
$$

In the calculation of (13)-(15) equations system, constant multipliers were marked by letter $z$ and a respective number, for example, in Eqns (13)-(15) the following constant multipliers were distinguished:

$$
\begin{aligned}
& z_{1}=I_{\text {sol }} \cdot \alpha_{e c . s e}+\Delta L_{n e t} \cdot \varepsilon_{\text {ec.se }} ; \\
& z_{2}=0.5 / l_{x} \cdot \mathrm{c}_{\text {air }} \cdot \rho_{\text {air }} \cdot v_{\text {a.g.air }} \cdot \delta_{\text {a.g. }} ; \\
& z_{3}=1 /\left(R_{\text {ins }}+1 / h_{\text {si }}\right) .
\end{aligned}
$$

Having evaluated constant multipliers $z$, (13)-(15) Eqns system may be rewritten in the following manner:

$$
\begin{aligned}
& z_{1}=h_{\text {ec.se }} \cdot\left(\theta_{\text {ec.se }}-\theta_{e}\right)+h_{\text {ec.si, },} \cdot\left(\theta_{\text {ec.se }}-\theta_{\text {a.g.air }}\right) \\
& +h_{\text {ec-ins, } r} \cdot\left(\theta_{\text {ec.se }}-\theta_{\text {ins.se }}\right) \text {; } \\
& h_{\text {ec.si,c }} \cdot\left(\theta_{\text {ec.se }}-\theta_{\text {a.g.air }}\right)=z_{2} \cdot\left(\theta_{\text {a.g.air }}-\theta_{e}\right)+ \\
& h_{\text {ins.se, }} \cdot\left(\theta_{\text {a.g.air }}-\theta_{\text {ins.se }}\right) \text {; } \\
& h_{\text {ec-ins, }, r} \cdot\left(\theta_{\text {ec.se }}-\theta_{\text {ins.se }}\right)+h_{\text {ins.se, },} \cdot\left(\theta_{\text {a.g.air }}-\theta_{\text {ins.se }}\right)= \\
& z_{3} \cdot\left(\theta_{\text {ins.se }}-\theta_{i}\right) \text {. }
\end{aligned}
$$

After solving (13)-(15) Eqns system, such formulas for calculating the temperatures of the air gap in the ventilated envelope $\theta_{\text {a.g.air }}$, external surface of thermal insulation layer $\theta_{\text {ins.se }}$, and external surface of external coating of the envelope $\theta_{\text {ec.se }}$ in the distance $l_{x}$ (when $l_{x} \leq 0.5 \cdot l_{\text {a.g. }}$.) from the entrance of air into the gap were derived:

$$
\begin{aligned}
& \theta_{\text {a.g.air }}=\left(z_{8} \cdot \theta_{e}+z_{14} \cdot z_{8} \cdot \theta_{e}-z_{14} \cdot z_{10} \cdot \theta_{i}+\right. \\
& \left.z_{4}+z_{5} \cdot \theta_{e}+z_{15} \cdot z_{8} \cdot \theta_{e}-z_{15} \cdot z_{10} \cdot \theta_{i}\right) /\left(z_{12}+z_{14} \cdot z_{11}+\right. \\
& \left.z_{14} \cdot z_{8}+z_{14} \cdot z_{9}+z_{14}+z_{15} \cdot z_{11}+z_{15} \cdot z_{8}+z_{15} \cdot z_{9}+z_{15}\right) \\
& \theta_{\text {ins.se }}=1 / z_{13} \cdot\left(z_{8} \cdot \theta_{e}-z_{10} \cdot \theta_{i}-z_{11} \cdot \theta_{\text {a.g.air }}-\right. \\
& \left.z_{8} \cdot \theta_{\text {a.g.air }}-z_{9} \cdot \theta_{\text {a.g.air }}-\theta_{\text {a.g.air }}\right) ; \\
& \theta_{\text {ec.se }}=z_{4}+z_{5} \cdot \theta_{e}+z_{6} \cdot \theta_{\text {a.g.air }}+z_{7} \cdot \theta_{\text {ins.se, }}
\end{aligned}
$$

where:

$$
\begin{gathered}
z_{4}=z_{1} /\left(h_{e c . s e}+h_{e c . s i, c}+h_{e c-i n s, r}\right) ; \\
z_{5}=h_{e c . s e}\left(h_{e c . s e}+h_{e c . s i, c}+h_{e c-i n s, r}\right) ; \\
z_{6}=h_{e c . s i, c} /\left(h_{e c . s e}+h_{e c . s i, c}+h_{e c-i n s, r}\right) ; \\
z_{7}=h_{e c-i n s, r} /\left(h_{e c . s e}+h_{e c . s i, c}+h_{e c-i n s, r}\right) ; \\
z_{8}=z_{2} / h_{e c . s i, c} ; \\
z_{9}=h_{\text {ins.se }, c} / h_{\text {ec.si }, c} ;
\end{gathered}
$$




$$
\begin{gathered}
z_{10}=z_{3} / h_{e c-i n s, r} ; \\
z_{11}=h_{\text {ins.se }, \mathrm{c}} / h_{e c-i n s, r} ; \\
z_{12}=z_{8}+z_{9}+1-z_{6} ; \\
z_{13}=z_{11}-z_{9}-z_{10}-1 ; \\
z_{14}=z_{9} / z_{13} ; \\
z_{15}=z_{7} / z_{13} .
\end{gathered}
$$

The accuracy of the calculations according to the presented formulas is greatly influenced by the values of heat transmittance coefficients which are not constant. In turn, they are affected by various temperatures and other impacts on the surfaces of the envelope. For this reason, the estimation of heat transmittance coefficients is discussed below of this paper.

\section{Heat transmission coefficients of the surfaces of the envelope}

\subsection{Heat transmission coefficient of the external surface of the envelope}

Heat transmittance coefficient of the external surface of the envelope is calculated by summing up convective and radiation heat transmittance coefficients, $h_{e c . s e, r}$ and $h_{\text {ec.se, } c}$ respectively (EN ISO 6946:2007):

$$
h_{e c . s e}=h_{e c . s e, r}+h_{e c . s e, c} \text {. }
$$

Similarly, convective heat transmittance coefficient of the external surface of the ventilated envelope $h_{\text {ec.se.c }}\left(\mathrm{W} /\left(\mathrm{m}^{2} \cdot \mathrm{K}\right)\right)$ may be estimated as follows (EN ISO 6946:2007):

$$
h_{\text {ec.se }, c}=4+4 \cdot v_{w},
$$

where: $v_{w}-$ wind speed, $\mathrm{m} / \mathrm{s}$.

When the temperatures of external air and external surface of the envelope are known, radiation heat transmittance coefficient of the external surface may be calculated in the following manner (EN ISO 6946:2007):

$$
h_{e c . s e, r}=4 \cdot \sigma \cdot T_{m}{ }^{3} \cdot \varepsilon_{e c . s e},
$$

where: $T_{m}$ - the average of temperatures of the environment and external surface of external coating of the envelope, ${ }^{\circ} \mathrm{K} ; \varepsilon_{e c . s e}-$ long-wave radiation emissivity of the external surface of external coating of the envelope.

When the temperatures of external air and external surface of the envelope are unknown, the given equation, which holds that the average between the temperatures of the environment and surface is $10{ }^{\circ} \mathrm{C}$, may be applied for the calculation of radiation heat transmittance coefficient of the envelope surface $h_{s e, r}\left(\mathrm{~W} /\left(\mathrm{m}^{2} \cdot \mathrm{K}\right)\right)$ :

$$
h_{s e, r}=5 \cdot \varepsilon_{s e} \text {. }
$$

When the temperature reaches $10{ }^{\circ} \mathrm{C}$, radiation heat transmittance coefficient of the envelope surface changes about 1.1 times (EN ISO 6946:2007). Thus, if the external temperature is known and the temperature of the external surface of the envelope is not, the coefficient may be calculated by a more accurate Eqn (40) which, differently from Eqn (39), employs external temperature $T_{e}(\mathrm{~K})$ instead of $T_{m}(\mathrm{~K})$ :

$$
h_{e c . s e, r}=4 \cdot \sigma \cdot T_{e}^{3} \cdot \varepsilon_{e c . s e}
$$

\subsection{Heat transmittance coefficients of the boundary surfaces of the ventilated air gap}

Convective heat transmittance coefficients of the boundary surfaces of the ventilated air gap $h_{r c . s i, c}$ and $h_{\text {ins.se,c }}$ $\left(\mathrm{W} /\left(\mathrm{m}^{2} \cdot \mathrm{K}\right)\right)$ can be calculated using Eqn (38) which requires the speed of air moving in the gap $v_{\text {a.g.air }}(\mathrm{m} / \mathrm{s})$, rather than wind speed $v_{w}$.

Radiation heat transmittance coefficients of the boundary surfaces of the gap $h_{e c-i n s, r}\left(\mathrm{~W} /\left(\mathrm{m}^{2} \cdot \mathrm{K}\right)\right)$ could be accurately estimated only if the temperatures of the external coating and thermal insulation layer of the envelope $\theta_{r c . s i}$ and $\theta_{i n s . s e}$ were known. The following formula could be used in such case:

$$
\begin{gathered}
h_{\text {ec-ins, } r}=C_{o} \cdot\left[\left(T_{\text {ec.si }} / 100\right)^{4}-\left(T_{\text {ins.se }} / 100\right)^{4}\right] / \\
\left(T_{\text {ec.si }}-T_{\text {ins.se }}\right) /\left(1 / \varepsilon_{\text {ec.si }}+1 / \varepsilon_{\text {ins.se }}-1\right) .
\end{gathered}
$$

However, if the surface temperatures of the external coating and thermal insulation layer of the envelope $\theta_{r c . s i}$ and $\theta_{\text {ins.se }}$ are not known, $h_{e c-i n s, r}\left(\mathrm{~W} /\left(\mathrm{m}^{2} \cdot \mathrm{K}\right)\right)$ may be calculated as follows:

$$
h_{e c-i n s, r}=4 \cdot \sigma \mathrm{T}_{e}^{3} /\left(1 / \varepsilon_{e c . s i}+1 / \varepsilon_{i n s . s e}-1\right) \text {. }
$$

\section{Experimental research}

\subsection{Description of the experimental envelopes}

The aim of the experimental research is to obtain data on factual temperatures $\theta_{\text {a.g.air }}, \theta_{\text {ins.se }}$ and $\theta_{\text {ec.se }}$ as well as to evaluate the accuracy of their calculations by the derived formulas. The type of the envelope and experimental conditions were chosen aiming at the experimental estimation of possible big changes in the temperatures $\theta_{\text {a.g.air }}, \theta_{\text {ins.se }}$ and $\theta_{\text {ec.se }}$ and seeking for objective evaluation of the accuracy of their calculation. For this purpose, the results of experimental research on nearly-horizontal ventilated roofs of varied construction were employed since the temperature changes, caused by solar radiation and other climatic impacts, may be the greatest on this type of roofs. The paper presents the results of experimental research on four different-construction ventilated roofs; their principal scheme is given in Figure 3, whereas Tables 1 and 2 show the thermal-technical indicators of the materials, layers and their surfaces used for the roof constructions. 


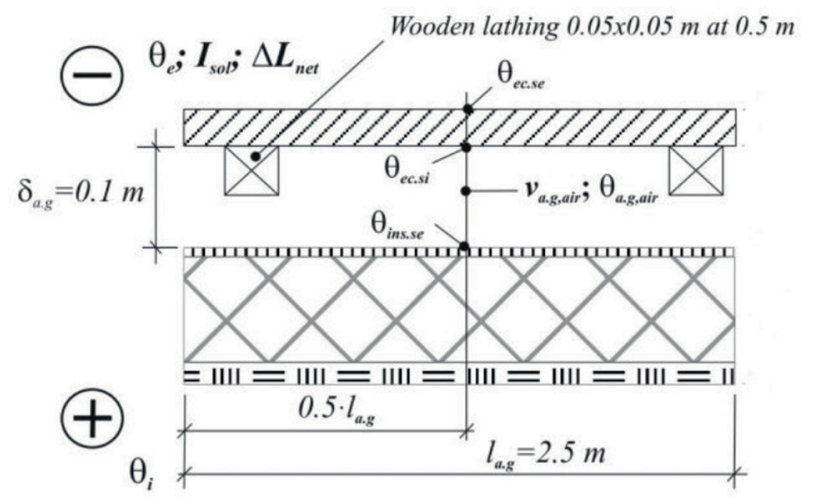

Fig. 3. Principal scheme of experimental cell roof construction

The construction of the ventilated air gap and coating of the roof were the same during all four experiments. $0.55 \mathrm{~mm}$ thick profiled steel sheets colored dark brown were used for roof coating. During experiments No. 1-No. 4, the construction of the roof between the ventilated air gap and premises was changed: starting from the side of the gap, it was composed of the following layers:

- experiment No. 1: $0.6 \mathrm{~mm}$ breather membrane + $200 \mathrm{~mm}$ mineral wool $+0.2 \mathrm{~mm}$ polyethylene film + $10 \mathrm{~mm}$ chipboard;

- experiment No. 2: $0.4 \mathrm{~mm}$ heat reflective film + $0.6 \mathrm{~mm}$ breather membrane $+200 \mathrm{~mm}$ mineral wool + $0.2 \mathrm{~mm}$ polyethylene film $+10 \mathrm{~mm}$ chipboard;

- experiment No. 3: $0.4 \mathrm{~mm}$ heat reflective film + $10 \mathrm{~mm}$ cement-sawdust board $+0.6 \mathrm{~mm}$ breather membrane $+200 \mathrm{~mm}$ mineral wool $+0.2 \mathrm{~mm}$ polyethylene film $+10 \mathrm{~mm}$ chipboard;

- experiment No. 4: $10 \mathrm{~mm}$ cement-sawdust board + $0.6 \mathrm{~mm}$ breather membrane $+200 \mathrm{~mm}$ mineral wool + $0.2 \mathrm{~mm}$ polyethylene film $+10 \mathrm{~mm}$ chipboard.

\subsection{Experimental conditions and results}

Experiments were carried out in real climate conditions in summer. Since the aim was to determine the biggest possible changes in the temperatures $\theta_{\text {a.g.air }}, \theta_{\text {ins.se }}$ and $\theta_{\text {ec.se }}$ of the examined constructions, the experiments were performed during summer periods when a great impact of solar radiation and outdoor temperature is expected.

During the experiments, constant temperature at the internal side of the examined ventilated roofs and singledirection heat flow through the examined envelopes were preserved. Moreover, according to the local climate data, it was known that the night temperature may fall down to $12{ }^{\circ} \mathrm{C}$ during the experimental period. For this reason, constant temperature close to $10{ }^{\circ} \mathrm{C}$ was preserved at the internal side of the envelopes.

A digital climate station was used for recording climatic indicators at the experimental site. The temperatures of the examined envelopes were measured using thermal couples and digital temperature sensors, while air speed in the ventilated air gap was estimated by air speed sensors. Digital experimental control and data storage equipment was employed for recording the data of the climate station and other sensors every second, calculating 1 minute average and then transferring them to the data storage block.

As it may be seen, the emissivity and mass of the external surface of thermal insulation layer were changed during experiments No. $1-$ No. 4 , i.e. the aim was to obtain results from a broad variation range of thermal-technical properties of the construction.

Tables 1 and 2 show the thermal-technical indicators of the materials, layers and their surfaces used for the roof constructions. Table 3 presents average daily data obtained during experiments No. 1-No. 4.

\section{Analysis of experimental research and calculation data}

Average daily and hourly experimental and measurement data were analyzed by taking into consideration the fact that the accuracy in calculating the radiation heat transmittance coefficients of the surfaces $h_{\text {ec.se.r }}$ and $h_{e c-i n s, r}$ has an impact on the accuracy of the data. The coefficients may be precisely estimated following Eqns (39) and (42), or Eqns (41) and (43) for approximate calculation. Thus, in the initial stage of data analysis, the errors emerging due to the use of the latter formulas were estimated.

Having analyzed the average daily data of all experimental research and calculations, it was determined that due to the use of approximate Eqns (41) and (43) for the calculations of the coefficients $h_{\text {ec.se.r }}$ and $h_{\text {ec-ins, } r \text {, }}$ only a very small absolute error, i.e. from $-0.3{ }^{\circ} \mathrm{C}$ to $0.2{ }^{\circ} \mathrm{C}$, can occur in the calculation of temperatures $\theta_{\text {a.g.air }}, \theta_{\text {ins.se }}$ and $\theta_{\text {ec.se }}$. In contrast, the analysis of average hourly data of all experimental research and

Table 1. Absorption coefficients for solar radiation and emissivity of the surfaces

\begin{tabular}{lcc}
\hline Material and surface & $\begin{array}{c}\text { Absorption coefficient of a surface } \\
\text { for solar radiation, } \alpha\end{array}$ & $\begin{array}{c}\text { Emissivity of a surface for } \\
\text { long-wave thermal radiation, } \varepsilon\end{array}$ \\
\hline External surface of the roof covering & 0.7 & 0.88 \\
\hline Internal surface of the roof covering & - & 0.77 \\
\hline External surface of the breather membrane & - & 0.69 \\
\hline External surface of the cement-sawdust board & - & 0.74 \\
\hline Surface of the heat reflective film & - & 0.09 \\
\hline
\end{tabular}


Table 2. Thermal-technical indicators of the roof between the ventilated air gap and premises

\begin{tabular}{|c|c|c|c|c|c|c|c|}
\hline \multirow[t]{2}{*}{ Material } & \multirow{2}{*}{$\begin{array}{l}\text { Thick- } \\
\text { ness, mm }\end{array}$} & \multirow{2}{*}{$\begin{array}{l}\text { Design thermal } \\
\text { conductivity, } \\
\mathrm{W} /(\mathrm{m} \cdot \mathrm{K})\end{array}$} & \multirow{2}{*}{$\begin{array}{l}\text { Thermal } \\
\text { resistance, } \\
\left(\mathrm{m}^{2} \cdot \mathrm{K}\right) / \mathrm{W}\end{array}$} & \multicolumn{4}{|c|}{$\begin{array}{l}\text { Thermal resistance of roof construction layers } \\
\text { between air gap and premises }\left(\mathrm{m}^{2} \cdot \mathrm{K}\right) / \mathrm{W}\end{array}$} \\
\hline & & & & Exp. No. 1 & Exp. No. 2 & Exp. No. 3 & Exp. No. 4 \\
\hline Heat reflective film & 0.4 & - & 0.02 & - & 0.02 & 0.02 & - \\
\hline Cement-sawdust board & 14 & 0.21 & 0.07 & - & - & 0.07 & 0.07 \\
\hline $\begin{array}{l}\text { Breather membrane pressed } \\
\text { on one surface of the roof } \\
\text { construction layer }\end{array}$ & 0.6 & - & 0.02 & 0.02 & - & - & - \\
\hline $\begin{array}{l}\text { Breather membrane between } \\
\text { to layers of roof construction }\end{array}$ & 0.6 & - & 0.04 & - & 0.04 & 0.04 & 0.04 \\
\hline Mineral wool & 200 & 0.034 & 5.88 & 5.88 & 5.88 & 5.88 & 5.88 \\
\hline Polyethylene film & 0.2 & - & 0.04 & 0.04 & 0.04 & 0.04 & 0.04 \\
\hline \multirow[t]{2}{*}{ Chipboard } & 10 & 0.13 & 0.08 & 0.08 & 0.08 & 0.08 & 0.08 \\
\hline & & & $\mathbf{R}_{\text {ins }}:$ & 6.02 & 6.06 & 6.13 & 6.11 \\
\hline
\end{tabular}

Table 3. Average daily data obtained during experiments No. 1-No. 4

\begin{tabular}{lccccccccc}
\hline Experimental stage & $\begin{array}{c}\theta_{e}, \\
{ }^{\circ} \mathrm{C}\end{array}$ & $\begin{array}{c}\theta_{i}, \\
{ }^{\circ} \mathrm{C}\end{array}$ & $\begin{array}{c}I_{\text {sol, }}, \\
\mathrm{W} / \mathrm{m}^{2}\end{array}$ & $\begin{array}{c}\Delta L_{\text {net }}, \\
\mathrm{W} / \mathrm{m}^{2}\end{array}$ & $\begin{array}{c}v_{w}, \\
\mathrm{~m} / \mathrm{s}\end{array}$ & $\begin{array}{c}v_{\text {a.g.air, }}, \\
\mathrm{m} / \mathrm{s}\end{array}$ & $\begin{array}{c}\theta_{\text {ec.se }}, \\
{ }^{\circ} \mathrm{C}\end{array}$ & $\begin{array}{c}\theta_{\text {a.g.air, }}, \\
{ }^{\circ} \mathrm{C}\end{array}$ & $\begin{array}{c}\theta_{\text {ins.se }}, \\
{ }^{\circ} \mathrm{C}\end{array}$ \\
\hline Exp. No. 1 & 22.50 & 9.83 & 332 & -50.46 & 2.27 & 0.19 & 29.75 & 25.62 & 26.94 \\
\hline Exp. No. 2 & 21.46 & 9.82 & 327 & -53.34 & 1.24 & 0.11 & 32.82 & 26.96 & 23.74 \\
\hline Exp. No. 3 & 22.83 & 9.81 & 242 & -35.15 & 1.76 & 0.19 & 29.69 & 26.45 & 24.04 \\
\hline Exp. No. 4 & 23.26 & $9 ., 81$ & 307 & -47.54 & 1.92 & 0.21 & 30.11 & 25.78 & 27.29 \\
\hline
\end{tabular}

calculations demonstrated that the absolute errors may be greater: from $-0.6{ }^{\circ} \mathrm{C}$ to $-1.6{ }^{\circ} \mathrm{C}$ in the calculation of temperature $\theta_{\text {ec.se }}$; from $-0.1{ }^{\circ} \mathrm{C}$ to $-0.5{ }^{\circ} \mathrm{C}$ in the calculation of temperature $\theta_{\text {a.g.air }}$; from $-0.3{ }^{\circ} \mathrm{C}$ to $0.4{ }^{\circ} \mathrm{C}$ in the calculation of temperature $\theta_{\text {ins.se }}$. The most important result of the calculations using Eqns (13)-(36) is the temperature of the surface of thermal insulation layer $\theta_{\text {ins.se }}$ which is necessary for the estimation of heat flow density through the ventilated envelope (see Eqn (9)). Therefore, the analysis showed that the errors in the calculation of $h_{e c . s e . r}$ and $h_{e c-i n s, r}$ applying Eqns (41) and (43) has only slight influence on the calculation accuracy of surface temperature $\theta_{\text {ins.se }}$ of thermal insulation layer.

In the second stage of data analysis the accuracy in calculating the temperatures $\theta_{\text {a.g.air }}, \theta_{\text {ins.se }}$ and $\theta_{\text {ec.se }}$ using Eqns (13)-(36) was assessed by comparing it with the results of experimental research. Moreover, coefficients $h_{\text {ec.se.r }}$ and $h_{e c-i n s, r}$ were calculated applying Eqns (41) and (43); average daily and hourly data were analyzed as well.

Table 3 shows the average daily data on climate and temperatures $\theta_{\text {a.g.air }}, \theta_{\text {ins.se }}$ and $\theta_{\text {ec.se }}$ determined during the experiments. The results of the measurement and calculation of average daily temperatures $\theta_{\text {a.g.air }}, \theta_{\text {ins.se }}$ and $\theta_{\text {ec.se }}$ are given in Figures $4 \mathrm{a}, \mathrm{b}$, c, while Figure 5 demonstrates the absolute errors in the calculation of these temperatures.
The absolute error in the calculation of the average daily temperature of roof coating $\theta_{\text {ec.se }}$, ventilated air gap $\theta_{\text {a.g.air }}$ and external surface of thermal insulation layer $\theta_{\text {ins.se }}$ are within the limits of $1.29^{\circ} \mathrm{C} ; 1.21^{\circ} \mathrm{C}$ and $2.71^{\circ} \mathrm{C}$ respectively. During the analysis of average hourly experimental and calculation data, the average hourly values of experimental data (climatic indicators and temperatures $\left.\theta_{\text {a.g.air }}, \theta_{\text {ins.se }}, \theta_{\text {ec.se }}\right)$ were estimated; similarly, the average hourly temperatures $\theta_{\text {a.g.air }}, \theta_{\text {ins.se }}$ and $\theta_{\text {ec.se }}$ were calculated applying Eqns (13)-(36). Figure 6 shows the average hourly outdoor temperatures $\theta_{e}$ and the data of experimental research and the calculation of temperatures $\theta_{\text {a.g.air }}, \theta_{\text {ins.se }}$ and $\theta_{\text {ec.se }}$ during experiments No. 1-No. 4.

Experimental and calculation data suggest that the surface emissivity of thermal insulation layer of the ventilated envelope has a significant impact on its temperature $\theta_{\text {ins.se }}$ If the emissivity of this surface is intense (Figs 6a, b, c, exp. No. 1, No. 4), the temperature $\theta_{\text {ins.se }}$ may be greater than the temperature of the ventilated air gap $\theta_{\text {a.g.air }}$ due to the radiation heat exchange in the gap. Conversely, the temperature $\theta_{\text {ins.se }}$ may be lower than the temperature $\theta_{\text {a.g.air }}$ due to the same reason, if the emissivity of the surface is low (Figs 6a, b, c, exp. No. 2, No. 3). Accordingly, it is essential to evaluate heat exchange processes in the ventilated envelopes in order to determine their thermal properties. 
Moreover, the accuracy of hourly calculation results are affected by massive surface thermal insulation layers, i.e. by their heat capacity (Figs 6a, b, c, exp. No. 3, No. 4). When a $14 \mathrm{~mm}$ thick cement-sawdust board was mounted on the surface of thermal insulation

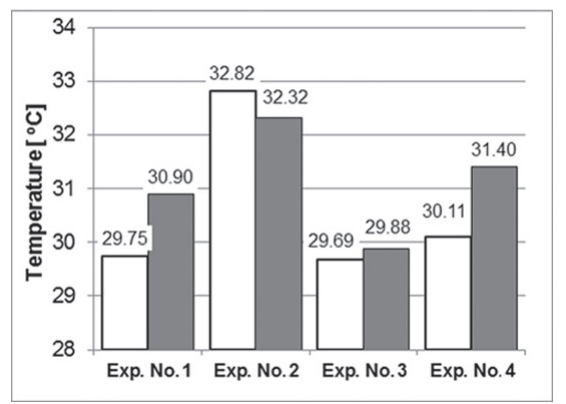

Fig. 4a. Results of calculation and measurement of average temperature of ventilated air gap (white - calculation, blackmeasured)

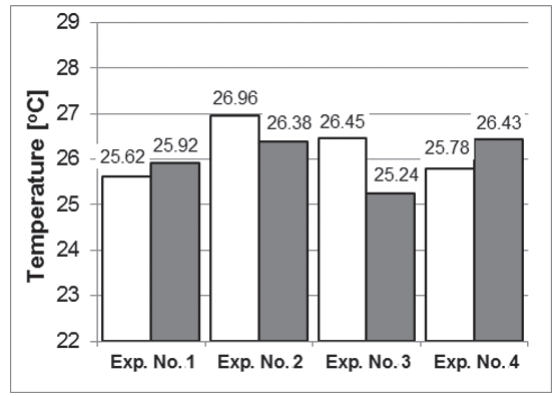

Fig. 4b. Results of calculation and measurement of average temperature of external surface of thermal insulation layer (white - calculation, black - measured)

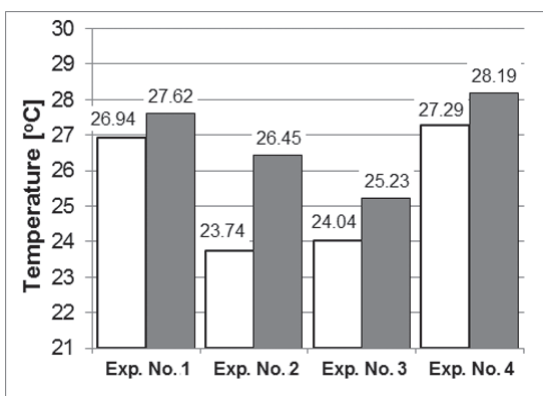

Fig. 4c. Results of calculation and measurement of average temperature of roof coating (white - calculation, blackmeasured) layer, factual changes in temperature $\theta_{\text {ins.se }}$ were recorded 2 hours later than calculated (Fig. 6. exp. No. 3, No. 4). Thus, the formulas suggested for the calculation of hourly temperature $\theta_{\text {ins.se }}$ should be applied carefully.

Eqs (13)-(36) for the calculation of temperatures $\theta_{\text {a.g.air }}, \theta_{\text {ins.se }}$ and $\theta_{\text {ec.se }}$ were derived from the equation system that describes heat exchange in steady-state conditions, whereas the experiments were carried out in real, that is, in variable climatic conditions. Regardless of this, the calculation results of temperatures $\theta_{\text {a.g.air }}$, $\theta_{\text {ins.se }}$ and $\theta_{\text {ec.se }}$ rather accurately represent the temperature changes in the ventilated envelopes in real climatic conditions.

\section{Conclusions}

During the process of heat exchange balance equation solution, the equations were simplified by introducing the following restriction into the formulas for the calculation of temperatures $\theta_{\text {a.g.air }}, \theta_{\text {ins.se }}$ and $\theta_{\text {ec.se }}$ : the equations may only be applied for the ventilated envelopes with steel or similar coatings as their external layers, i.e. coatings having small heat capacity and minor difference between the external and internal surface temperatures.

The formulas derived for the calculation of the temperatures of the ventilated air gap of the envelopes $\theta_{\text {a.g.air }}$, external surface of thermal insulation layer $\theta_{\text {ins.se }}$ and external surface of envelope coating $\theta_{\text {ec.se }}$ rather accurately match the results of experimental research. It demonstrated that the absolute error in the calculations of the average daily temperature of external surface of the ventilated envelope $\theta_{\text {ec.se }}$ does not exceed $1.29^{\circ} \mathrm{C}$; similarly, the temperatures of the ventilated air gap $\theta_{\text {a.g.air }}$ and external surface of thermal insulation layer of the envelope $\theta_{\text {ins.se }}$ are within the limits of $1.21{ }^{\circ} \mathrm{C}$ and $2.71{ }^{\circ} \mathrm{C}$ respectively.

Massive surface thermal insulation layers (heat capacity) influences the accuracy of hourly calculation results obtained by the derived formulas; thus, this must be taken into account during the calculation of hourly temperatures $\theta_{\text {ins.se }}$.

The derived equations enable the calculation of the temperatures of the ventilated envelopes $\theta_{\text {a.g.air }}, \theta_{\text {ins.se }}$ and $\theta_{\text {ec.se }}$ in the distance which does not exceed a half

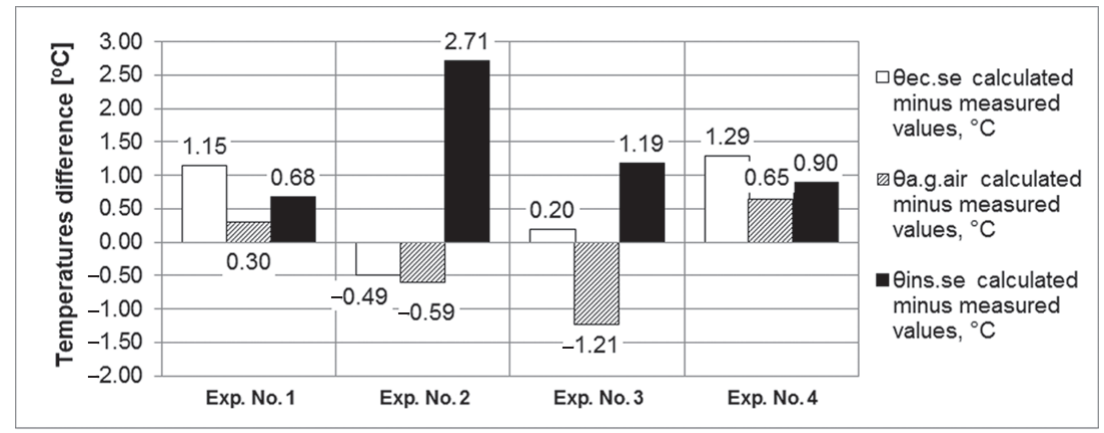

Fig. 5. Absolute error in the calculation of average daily temperatures $\theta_{\text {a.g.air }}, \theta_{\text {ins.se }}$ and $\theta_{\text {ec.se }}$ by Eqns (13)-(36) 


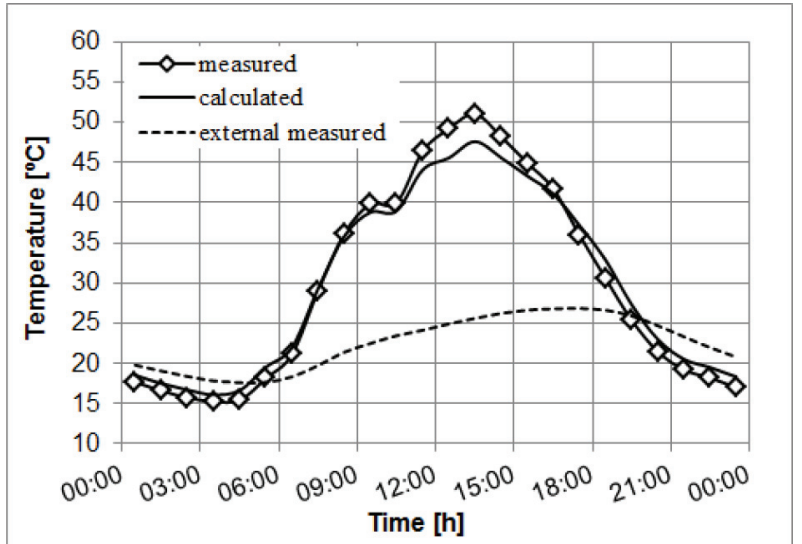

Fig. 6a. Average hourly temperatures of ventilated air gap and external air

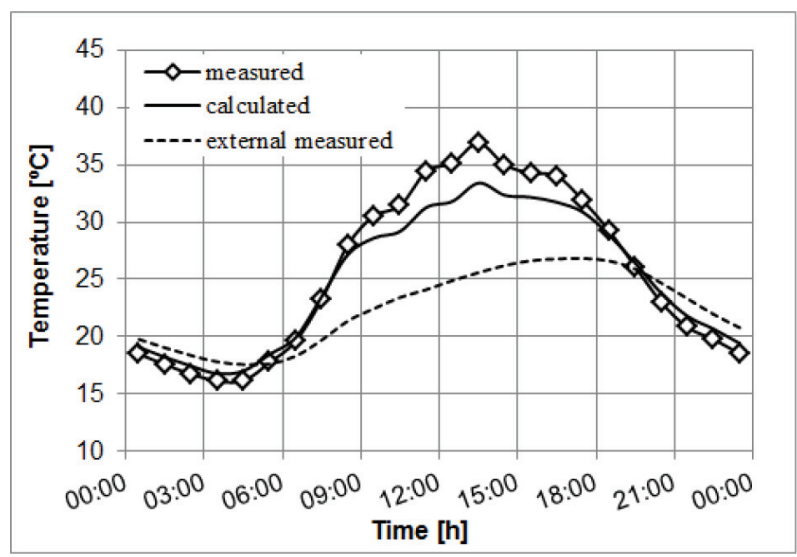

Fig. 6b. Average hourly temperatures of external surface of thermal insulation layer and external air

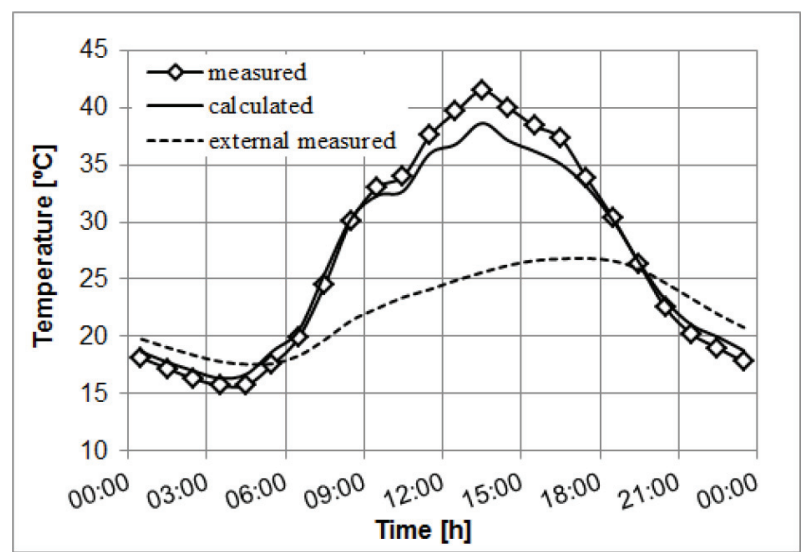

Fig. 6c. Average hourly temperature of roof coating and external air

of the ventilated air gap length measuring from the air entrance into the gap. However, this restriction does not impede the estimation of the average thermal indicators of the ventilated envelope.

\section{References}

Banionis, K.; Stankevičius, V.; Monstvilas, E. 2011. Heat exchange in the surface of lightweight steel roof coatings, Journal of Civil Engineering and Management 17(1): 88-97. http://dx.doi.org/10.3846/13923730.2011.556180

Ciampi, M.; Leccese, F.; Tuoni, G. 2003. Ventilated facades energy performance in summer cooling of buildings, Solar Energy 75(6): 491-502. http://dx.doi.org/10.1016/j.solener.2003.09.010

Ciampi, M.; Leccese, F.; Tuoni, G. 2005. Energy analysis of ventilated and microventilated roofs, Solar Energy 79(2): 183-192. http://dx.doi.org/10.1016/j.solener.2004.08.014

Directive 2010/31/EU of the European Parliament and of the Council of May 192010 on the energy performance of buildings, Official Journal of the European Union L $153 / 13-153 / 35$.

EN ISO 13790:2008 Energy performance of buildings. Calculation of energy use for space heating and cooling. International Organization for Standardization, Brussels, 2008. 32 p.

EN ISO 6946:2007 Building components and building lements. Thermal resistance and thermal transmittance-Calculation method. International Organization for Standardization, Brussels, 2007. 28 p.

Filho, J. P.; Henriquez, J. R.; Dutra, J. C. C. 2011. Effects of coefficients of solar reflectivity and infrared emissivity on the temperature and heat flux of horizontal flat roofs of artificially conditioned nonresidential buildings, Energy and Buildings 43(2-3): 440-445.

http://dx.doi.org/10.1016/j.enbuild.2010.10.007

Infield, D.; Mei, L.; Eicker, U. 2004. Thermal performance estimation for ventilated PV facades, Solar Energy 76(1-3): 93-98. http://dx.doi.org/10.1016/j.solener.2003.08.010

Monstvilas, E.; Stankevičius, V.; Bliudžius, R. 2005. The impact of climate parameters on air movement in ventilated roofs air gap, in Proc. of the Final Conference of COST Action C12, 20-22 January 2005, Innsbruck, Austria. Taylor \& Francis Group, 573 - 578.

Roels, S.; Deurinck, M. 2011. The effect of a reflective underlay on the global thermal behaviour of pitched roofs, Building and Environment 46(1): 134-143. http://dx.doi.org/10.1016/j.buildenv.2010.07.005

Synnefa, A.; Santamouris, M.; Livada, I. 2006. A study of the thermal performance of reflective coatings for the urban environment, Solar Energy 80(8): 968-981. http://dx.doi.org/10.1016/j.solener.2005.08.005

Synnefa, A.; Santamouris, M.; Apostolakis, K. 2007. On the development, optical properties and thermal performance of cool colored coatings for the urban environment, Solar Energy 81(4): 488-497. http://dx.doi.org/10.1016/j.solener.2006.08.005

Shi, Z.; Zhang, X. 2011. Analyzing the effect of the longwave emissivity and solar reflectance of building envelopes on energy-saving in buildings in various climates, Solar Energy 85(1): 28-37.

http://dx.doi.org/10.1016/j.solener.2010.11.009

Suehrcke, H.; Peterson, E. L.; Selby, N. 2008. Effect of roof solar reflectance on the building heat gain in a hot climate, Energy and Buildings 40(12): 2224-2235. http://dx.doi.org/10.1016/j.enbuild.2008.06.015

Susanti, L.; Homma, H.; Matsumoto, H. 2011. A naturally ventilated cavity roof as potential benefits for improving thermal environment and cooling load of a factory building, Energy and Buildings 43(1): 211-218. http://dx.doi.org/10.1016/j.enbuild.2010.09.009

Van Dijk, H.; Spiekman, M.; Wilde, P. 2005. A monthly method for calculating energy performance in the context of European building regulations, in Ninth International IBPSA Conference, 15-18 August 2005, Montréal, Canada, 255-262. 
Edmundas MONSTVILAS. Doctor, Senior Researcher at the Laboratory of Thermal Building Physics of the institute of Architecture and Construction, KTU. Research interests: heat transfer and thermal insulation, technical properties of thermal insulation products.

Karolis BANIONIS. Doctor, Researcher at the Laboratory of Thermal Building Physics of the institute of Architecture and Construction, KTU. Research interests: heat transfer and thermal insulation, thermal impacts of solar radiation, determination of air permeability of buildings.

Jurga PODERYTE். Doctor, Research worker of the Laboratory of Thermal Building Physics at the Institute of Architecture and Construction, Kaunas University of Technology. Research interests: heating, ventilating and air conditioning.

Raimondas BLIŪDŽIUS. Doctor, Full Professor, head of Laboratory of Thermal Building Physics at the Institute of Architecture and Construction, KTU. Research interests: thermal processes in building, thermal properties of building materials and elements.

Arūnas BURLINGIS. Doctor, Senior Researcher at the Laboratory of Thermal Building Physics of the institute of Architecture and Construction, KTU. Research interests: heat transfer and thermal insulation, technical properties of thermal insulation products. 